\title{
\#SELF-CONCEPT AND THE EDUCATION OF GEOGRAPHICALLY ISOLATED CHILDREN
}

\author{
${ }^{*}$ K.E. Sinclair
}

Let me begin with the proposition that a basic need of people is to enhance and maintain their feelings of self-esteem and selfregard. Those feelings are among our most precious possessions; throughout our lives we strive to enhance that level of self-regard and we go to considerable trouble to ensure that our self-regard is not damaged in any significant way. A person's self-concept can be viewed as a store of self-perceptions; it consists of answers to such questions as, Who am I? What do I believe in and value? What do I want to get out of life? What are my strengths and weaknesses? How capable a person am I? Self-esteem has to do with how negatively or positively we regard these self-attributes, how adequate or inadequate we feel as individuals, and the level of our self-regard. Children develop ideas about how adequate and effective they are from the reactions of other people to them. They see themselves in the light of the attitudes, comments, and other reactions expressed towards them by parents, teachers, friends, and, increasingly with age, in the light of their own reactions to themselves as individuals. Their feelings of self-esteem, then, are associated with feelings about their competence, how adequate they feel in handling the different situations in which they find themselves. It is also associated with the extent to which they feel they are able to live up to ideals of what is right and what is wrong, and with the extent to which they perceive themselves to be accepted and loved by other people.

\section{UNDERSTANDING HUMAN NEEDS}

Maslow's needs hierarchy provides a very useful basis for understanding self-concept and its relationship to behaviour. Maslow (1970) speaks of a succession of needs that are important for the person to satisfy. His needs hierarchy may be represented diagrammatically (Fig.1) in terms of a pyramid in which the basic needs are at the bottom and the more complex, ultimate objectives of human

\# Reproduced from Perspectives on Affective Education in the NorthWest Region, North West Region Aboriginal Education Committe, Walgett, N.S.w. Dr Kenneth E. Sinclair, University of Sydney. 
existence are at the top. From basic to complex needs we have physiological needs, safety needs, needs for love and being accepted, esteem needs, knowledge needs and self-actualization.

Fig.1 Representation of Maslow's Needs Hierarchy

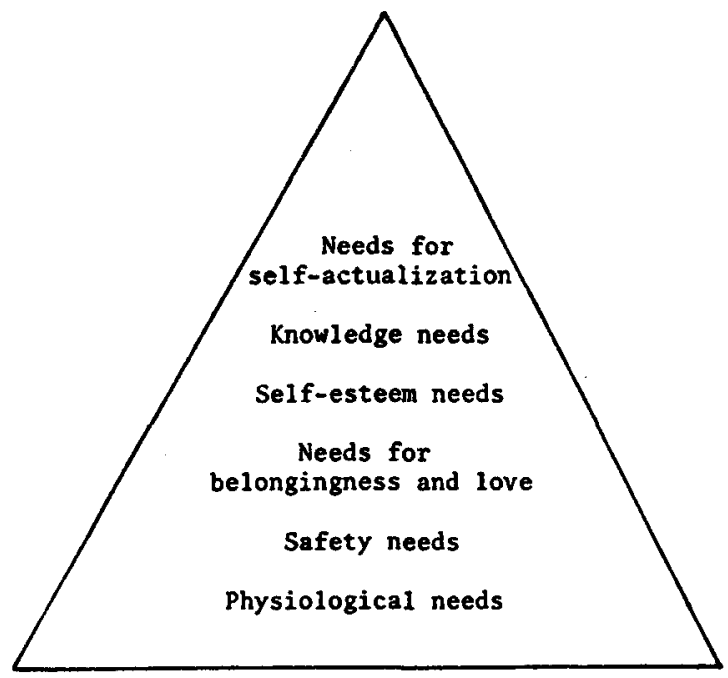

The physiological needs are those involved in maintaining basic body processes such as the intake of oxygen, food and liquid and the elimination of body wastes. There is a tendency in education to assume that those basic needs are already met in children. Quite often, however, especially with respect to children living in disadvantaged circumstances, they are not met. I remember watching a lesson at Bourke earlier this year in which a teacher was teaching a group of eight-year-olds. She showed the children a short film about a trip in space. She then brought the children into the centre of the room, sat them on a mat on the floor, and had them close their eyes and try to imagine what it would be like to be moving through space in a rocket. She asked Johnny what he could smell and Jane what she could feel, another child what he could see and another child what she could hear. It was quite magnificently done and after about ten or so minutes of this activity on the floor she asked the children to go back to their desks and write several sentences about a trip through space. When they got up, there were three children asleep on the floor.

That illustrates what happens when basic body processes are not satisfied: when children have to share beds, live in noisy surroundings, and are unable to get the necessary amount of sleep. That problem is often compounded by other problems in a significant number of children growing up in disadvantaged circumstances; hearing difficulties resulting from ear infections, seeing difficulties, malnutrition and so on. 
Safety Needs are satisfied in terms of freedom from physical abuse, bullying and so on. They also have a psychological aspect expressed in a need to know the limits of acceptable behaviour, so that rules, limits and a clear understanding of the expectations of the teacher are very important components. The need for love and a sense of belonging is expressed in a seeking out of praise, recognition and attention from peers and important adults such as parents and teachers. The next set of needs, self-esteem needs, has two particular aspects. One aspect is a need to succeed and to develop competencies that allow the person to cope with life's circumstances. In schooling this is expressed particularly in terms of need for achievement, a striving after success and competency in classroom achievement tasks which serve to enhance self-esteem. The other aspect of self-esteem, however, is the need to avoid failure which, when aroused, is expressed as anxiety. If the person is not able to achieve success and demonstrate competencies then the danger is that self-esteem will be eroded. These twin affective states of need for achievement and anxiety are very important for understanding classroom performance and behaviour.

After self-esteem comes knowledge needs and, of course, knowledge is a central concern of education. Curiosity is closely associated with knowledge needs. Curiosity is aroused in situations that challenge the person to understand and resolve problems, cope with novel experiences and information, and which engage the intrinsic interests of the person. Knowledge needs are also related to what is considered to be relevant for the immediate and future life of the person. Motivation to learn is likely to be increased when the knowledge involved is regarded as relevant and useful.

Teachers have a great deal of control over the extent to which these various needs are satisfied. Their behaviour will have important consequences for the extent to which children experience a sense of physical and psychological security at school, a sense of belonging and being accepted, a sense of being successful and competent as a person as against being a failure and incompetent, and a sense of understanding the world and one's place in it. Maslow makes it clear that for students to be able to concentrate attention on the higher level needs such as knowledge needs and school learning, they should have achieved a sense of satisfaction of the more basic needs. Thus students who are struggling to satisfy physiological needs or safety needs or needs to do with being accepted and loved will be primarily attending to those needs and their satisfaction, thus reducing substantially their attention to classroom learning tasks. 
It should also be recognised that the teachers' own sense of need satisfaction will influence the extent to which the needs of their students will be satisfied. If teachers feel inadequate themselves and vulnerable to fears of failure, they may take advantage of the greater vulnerability of their students to failure and to feelings of inadequacy. In this way they may attempt to sustain and protect their own self-feelings but it will be at the expense of the self-feelings of their students.

It will also be apparent that the affective states associated with need satisfaction such as anxiety, need for achievement, and curiosity are closely interrelated. On the one hand, experience of success and failure and the setting of realistic expectations are important in determining the relative strength of need for achievement and anxiety. On the other hand, the arousal of curiosity requires that classroom threat and anxiety be kept to a reasonably low level. The way the teacher distributes success and failure and associated praise and criticism, and the extent to which he/she is able to create an atmosphere that keeps personal threat to a minimum, will have an important bearing on the motivational states of the students.

\section{MOTIVATIONAL PATTERNS OF CHILDREN IN ISOLATED SCHOOLS}

Our studies reveal that patterns of motivational states tend to emerge in particular school populations. We have recently completed studies of students in inner-city (Turney, Inglies, Sinclair and Straton, 1978) and geographically isolated schools (Turney, Sinclair and Cairns, 1980) which had been classified as disadvantaged. Compared with students from more affluent middle-class suburbs in Sydney, students from these schools were found, as a group, to be lower in self-esteem, higher in anxiety and lower in need for achievement. The lower levels of self-esteem may be related to the more acute problems of living in these communities such as the problems of a personal, financial and occupational nature being experienced by the families of the children. The higher levels of anxiety may come as a surprise in that most often it is considered that the middle-class upwardly mobile child is likely to be more anxious about school performance. Our results and the results of overseas studies not unexpectedly dispute that possibility. The lower need for achievement of the students from disadvantaged schools is also understandable. If they are motivated by strong fears of failure it stands to reason that the degree to which they are hoping and striving for success is likely to be reduced. 
One further measure that we used was associated with the extent to which the children from the disadvantaged schools saw themselves as having personal control over learning and performance at school. Level of personal control, or locus of control as it is usually termed, is measured by asking students to explain why they succeed or fail on tasks at school. External locus of control is found in those who believe that they have little personal control over their environment and their destinies. In the classroom, blame for failure may be directed at the teacher, the difficulty of the task, bad luck and so on: in other words, achievement is attributed to external factors outside the person's control. Other children, however, may blame themselves for failure through not being smart enough or not trying hard enough or being lazy. These children attribute failure to internal factors and are said to adopt an internal locus of control. In a similar way success may be attributed to either internal or external factors.

As would be expected, those with an internal locus of control (especially one emphasizing the importance of effort) tend to be pupils with a high need for achievement who typically show more persistence and effort in relation to classroom tasks and generally superior achievement compared to pupils with a predominantly external locus of control. Other studies have identified pupils characterized by what has come to be called "learned help1essness". Such pupils are likely to give up in the face of failure and, compared to more perservering pupils, place significantly less emphasis on effort as a determinant of success and failure.

A tendency for disadvantaged groups of pupils to be characterized by external locus of control and "learned helplessness" has emerged in a number of studies. In our research we found students in the inner-city and in geographically isolated areas of New South Wales to be more external with respect to locus of control than middle-class students living in Sydney.

In our studies it has also been possible to gather information about performance levels of the students. The results reveal that the students in the inner-city and geographically isolated schools, as a group, are well behind other students in the state on a standardised measure of reading comprehension. When the reading scores are correlated with the motivational measures we find that those who are performing at or beyond the level expected of children of their age tend to be children who have the higher levels of selfesteem, lower levels of anxiety and an internal locus of control. In contrast, the lowest performers tended to be those with the lowest levels of self-esteem, highest levels of anxiety and an external locus of control. If we take the Aboriginal children in our isolated schools sample as a special group, we find that there is not 
too much difference between their motivational characteristics and those of the isolated children generally. The Aboriginal children do tend to reveal a more exaggerated pattern of motivational characteristics with somewhat lower levels of self-esteem and somewhat higher levels of anxiety but the difference is not particularly marked. There may well be different implications for teaching Aboriginal students however. One of our research students has recently completed a study at Wilcannia where he was interested in the question of the preference of Aboriginal children for particular learning modes - competitive, co-operative or individualised. He found that the Aboriginal children showed about the same degree of preference for the co-operative mode as the general population but far less acceptance of competitive modes of learning. This seems to be an important finding and one that has important practical implications for the education of Aboriginal students.

What are the classroom consequences of the motivational pattern found with geographically isolated students? The pattern found suggests that many of these children experience learned helplessness and a strong fear of failure. This motivational pattern may be expected to result in behaviour problems and reduced levels of performance in the classroom. Such children will tend to become preoccupied with the threat to self-esteem facing them which may lead to ego-protective defensive reactions such as rationalizing that the task is not really very important, or finding other ways in which self-esteem may be maintained, such as by behaviour that seeks attention from peers or the teacher. Thus apathetic attitudes and classroom misbehaviour, as well as lowered performance, may be traced to high anxiety levels and the need to maintain acceptable levels of self esteem. As shown in Fig.2, cycles of failure may be established when the learning experience at school is perceived principally in terms of fear of failure and/or as lacking in interest and relevance, which again was a common criticism made by students at isolated schools. Anxiety associated with low feelings of self-regard and an uninteresting and largely irrelevant curriculum may both lead to pupil apathy and misbehaviour. For the anxious pupil, this behaviour is designed to defend against the emotional hurt of further failure and may also be designed to win approval and status in the peer group and through this enhanced self-feeling. Teaching methods and a curriculum that are uninteresting and irrelevant may result in behaviour that seeks to induce some purpose and excitement into the classroom. Of course, as already discussed, both these states and their consequences may go hand-in-hand. If the vicious circles are to be broken the teacher will need to intervene so that fear of failure may be replaced by striving after success and boredom replaced by interest and curiosity. 
Fig. 2 Cycles of Failure

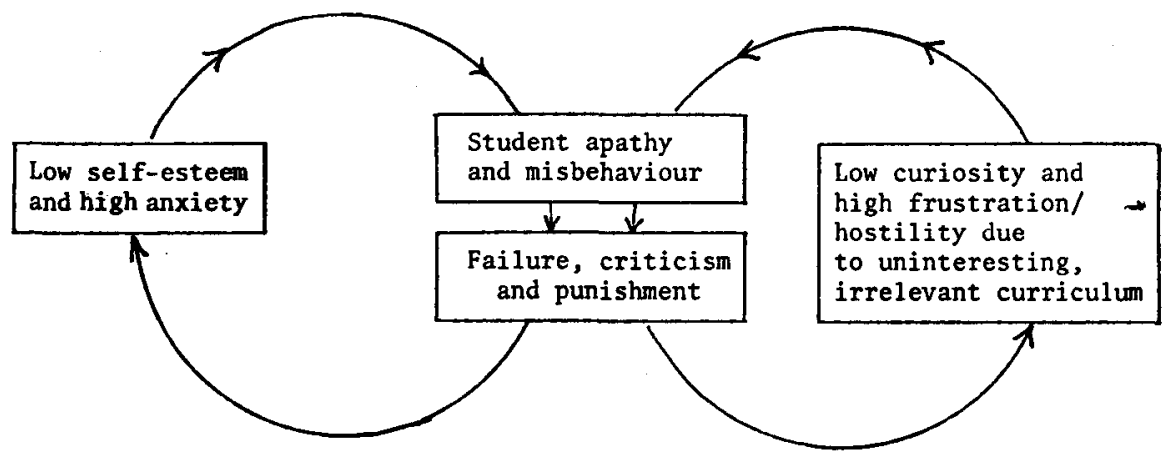

ANXIETY AND ITS MANAGEMENT

It should be clear that a key concept in understanding and nurturing self-feelings is anxiety and its management. Let us now look a little more closely at that concept. As already observed, anxiety is typically associated with threats to self-esteem. A common source of threat to self-esteem in the classroom will be evaluative situations. Tests and examinations at school are obvious examples, but anxiety will also be aroused when answering questions asked by the teacher, delivering reports to the class, taking part in drama, demonstrating at the chalk-board, completing essays and assignments and so on. Similarly, anxiety may be aroused in relation to social adequacy and success in dealing with interpersonal relationships. There are, then, a wide range of classroom situations and experiences that may arouse anxiety.

The amount of anxiety experienced varies from student to student. Some students have little tendency to react with anxiety while others will have a strong tendency to react with anxiety over a wide range of situations. Highly anxious students are typically very critical about themselves - their abilities, their appearance, their personalities and so on. This is an expression of their low self-esteem and feelings of worth. Their self-feelings are extremely vulnerable to further injury and hurt. Anxious students are also often overly dependent on their teachers and parents. They have a strong need to know precisely what is expected of them and just how they should proceed on a given task. Because of this they tend to ask many questions that attempt to clarify their teachers' expectations and the way they should be proceeding with the task at hand. In other words, they have difficulty in behaving independently in their work and study. They tend to like teachers who are warm and friendly towards them but who are fairly directive in their teaching methods and teach by telling. They find teaching methods that rely on them using initiative and independence in finding things out for themselves as too threatening. Interestingly enough the reverse is true for the student who finds little to worry about at school such a student performs best in the more challenging situation requiring initiative and independence. 
It is also apparent that anxiety is not just confined to the less able students who have difficulty in learning at school. Bright students may also be subject to high levels of anxiety although teachers may often fail to recognise this. Success is a relative thing. The very able student often strives to achieve a very high standard of performance, perhaps by coming in the top one or two places in the class or year. For them, therefore, doubts about being able to live up to those expectations may be just as great or even greater than for the less able student with modest expectations.

The anxiety response itself has a number of opponents (Sinclair, Heys, and Kemmis, 1974). On the one hand there are somatic responses that are aroused such as palmar sweating, dryness of the throat, increased heart beat and upset stomach. On the other hand there are worry responses that occur as the person ruminates about the difficulties faced in coping with the threat and the consequences of failure. When the level of anxiety aroused is high, these emotional and worry responses distract attention away from the task in hand. They may also be associated with defensive patterns of behaviour which may help preserve self-esteem but at the expense of successfully dealing with the task. The defensive behaviours may include daydreaming, showing off, and attention seeking, careless and impulsive work, and sometimes avoidance of threats at school by feigning sickness or even by truanting.

Most often, therefore, anxiety has been found to interfere with performance at school. Because high levels of anxiety are a particularly unpleasant experience they can also lead to a dislike of school and to a premature dropping out of school.

Studies show that anxiety is most disruptive when the task to be performed is a difficult one and it is important that the student do well, as in a final examination. Conversely, anxiety has least effect when the task is an easy one and when failure does not have serious personal consequence, as in a game-like performance situation. There is also evidence that high anxious students prefer a teacher-centred style of instruction rather than a student-centred style that requires them to use initiative and independence in finding things out for themselves. As has alrcady been discussed, high anxious students tend to have high dependency needs and prefer situations in which there are clear expectations about the task to be performed and how they should go about performing it. 
In an early study, Grimes and Allinsmith (1961) compared the early reading achievement of high and low anxious students when taught by either a highly structured phonic method or a more discovery demanding whole word method. They found that the type of teacher method used had little effect on the performance of low anxious students. The high anxious students, however, performed significantly better when they learned by the more structured phonic method. When the phonic method was used they performed as well as the low anxious students, however, they were significantly inferior to the low anxious students when the whole word method was used. This result is also consistent with the success achieved in teaching disadvantaged students to read using the teacher-directed Distar reading materials. As a group disadvantaged students (as was found with the geographically isolated students) tend to evidence relatively high levels of anxiety and fear of failure. Other studies have a1so produced similar findings. Trown and Leith (1975) and Dowaliby and Schumer (1973) found that high anxious students performed best when a teacher-centred technique was used that involved highly structured didactic teaching methods. Indeed their performance was superior to low anxious students when this method was used. The low anxious students on the other hand performed best and were superior to high anxious students when a student-centred technique was used involving discussion and student discovery.

\section{IMPLICATIONS FOR TEACHING}

What implications are there, then, for teaching children so that the disruptive effects of anxiety are controlled and the twin aims of increasing student self-esteem and performance are achieved? Two important ingredients of a workable teaching strategy are success and praise. Success experiences for the students will act to enhance self-esteem and will motivate further learning by increasing hope of success and need for achievement. Praise earned through successful achievement will contribute towards a sense of being accepted and belonging, and will generate feelings of pride. By carefully planning learning situations in the classroom in ways by which achievement comes within the capacities of each individual student, success and praise may gradually come to replace failure and criticism. Where the students show evidence of learned helplessness and anxiety, and it appears that this is the case with many geographically isolated students, teacliers should be sensitive to the needs of these students for dependence and a we11 organised and structured environment. If such dependency needs are met and the children are helped to experience success and to build up self-confidence they may be gradually encouraged to assume more responsibility and independence in their learning. Learned helplessness is such that they believe they have little personal control over learning and performance; 
learning and performance is largely a matter of luck or teacher favour or some other factor out of their control. It is important, therefore, that they are led to see a quite clear relationship between the amount of effort that they give in learning and the degree of success and failure experienced. In these ways, therefore, anxiety feelings may be reduced and more positive attitudes and patterns of behaviour encouraged. By developing and introducing curriculum materials of greater personal interest and relevance for the immediate and future lives of the students these positive achievement-related attitudes will be further enhanced. They will also be enhanced if their teachers show warmth, acceptance and support towards them and are prepared to use fairly well structured teaching techniques in which there is a minimum of ambiguity and uncertainty.

In recent years a number of teaching techniques have been developed which attempt to improve pupil self-concept and selfesteem quite directly. Let me recommend you to an interesting little book by Canfield and Wells called A Hundred Ways to Enhance Self Concept in the Classroom (1976). In that book the authors describe a number of exercises that will improve self-feelings. In one exercise pairs of students have a five-minute discussion during which they discuss their interests and what they feel they are good at. After the discussion each student tells the class what he or she has learned about the other student. The emphasis is very much on acknowledging positive aspects of student self-concept in public. Another exercise is used at the end of the day. In this exercise students are asked to talk briefly about a particular success experienced at school that day. Many other useful self-enhancement techniques are described in the book as well.

Finally, let me finish with a brief word about teacher needs. Our study of geographically isolated schools (Turney et al, 1980) revealed that the teachers themselves are confronted by many problems and considerable personal and occupational stress. Typically, teachers in isolated schools are inexperienced, often being in their first or second year of teaching, and mobile, only remaining in the community for 2 or 3 years. While they bring considerable enthusiasm and idealism to their work there is the danger that it will be stifled by the serious adjustment and teaching problems facing them. Many teachers told us of experiencing a type of culture shock when taking up their appointments. Their common background of a comfortable (even sheltered) suburban life in Sydney and successfill educational achievements in academically orientated and competitive high schools and universities clashed tremendously with the backgrounds and values of many of their students and the sense of isolation experienced in the communities to which they were sent. Their own personal problems of adjustment often increased their problems of 
adjusting their teaching to the needs of their students. It is difficult in such circumstances to devise and implement effective new teaching materials and approaches that are tailored to the very special needs of the students.

There is clearly a need for a greater proportion of experienced teachers with superior teaching skills in geographically isolated schools. As it is, the teachers interviewed complained about inadequate preparation in their teacher education programs for teaching assignments to such schools and also about the lack of support and guidance received as teachers in those schools. In particular, they drew attention to the need for special preparation and support in such areas as teaching Aboriginal children, understanding the needs, values and backgrounds of isolated rural children, motivating those children to learn, coping with discipline problems, teaching basic skills and dealing with remediation problems. Clearly the satisfaction of student needs is dependent on the prior satisfaction of basic teacher needs.

The problems discussed in this paper are serious but solutions may be found. There is increasing awareness of the particular needs of teachers in isolated schools and positive steps are being taken to satisfy those needs. As we have seen, our understanding of students in isolated schools is also growing and techniques for teaching them more effectively are emerging. There remains, however, the task for teachers to take the necessary initiatives that will meet more adequately the total needs of those students. Only through that will children in isolated communities come to enjoy the full satisfactions and benefits that may be obtained from their education. I hope some such initiatives will be an important outcome of this conference.

REFERENCES (and suggestions for further reading)

Canfield, J. and Wells, H.C., 1976: 100 Ways to Enhance Selfconcept in the classroom: a handbook for teachers and parents. Prentice Hall.

Covington, M.V. and Beery, R.G., 1976: Self-worth and School Learning. Holt, Rinehart and Winston.

Dowalihy, F.J. and Schumer, H.: Teacher-centre mode of college classroom instruction is related to manifest anxiety. Jourmal of Educational Psychology, 1973:65, 125-32.

Grimes, J.W. and Allinsmith, W.: Compulsivity, anxiety and school achievement. Merril-Palmer Quarterly, 1961:37, 247-71. 
Maslow, H.H., 1970: Motivation and Personality, 2nd Ed., Harper. Miller, J.P., 1976: Humanizing the classroom: Models of Teaching in Affective Education. Praeger.

Purkey, W.W., 1978: Inviting School Success: a Self-concept approach to teaching and learning. Wadsworth.

Ringness, T.A., 1975: The Affective Domain in Education. Little, Brown.

Sinclair, K.E., 1981: Knowing the child. In Turney, C. (Ed.): The Anatomy of Teaching. Novak.

Sinclair, K.E., Keys, T.A. and Kemmis, S. de C.: Anxiety and cognitive processes in problem solving. Australian Journal of Education, 1974:18, 239-54.

Trown, E.A. and Leith, G.0.M.: Decision rules for teaching strategies in primary schools; personality-treatment interactions. British Joumal of Educational Psychology, 1975:45, 130-40.

Turney, C., Inglis, C.B., Sinclair, K.E. and Straton, R.G., 1978: Inner-city Schools: Chizdren, Teachers and Parents. Sydney University Press.

Turney, C., Sinclair, K.E. and Cairns, L.G., 1980: Isolated Schools: Teaching, Learning and Transition to Work. Sydney University Press. 